\title{
Treatment of Rice Mill Wastewater Using Continuous Electrocoagulation Technique: Optimization and Modelling
}

\author{
Thirugnanasambandham Karichappan, Sivakumar Venkatachalam*, Prakash Maran Jeganathan, \\ and Kandasamy Sengodan \\ Department of Food Technology, Kongu Engineering College, Perundurai, Erode-638052, TN, India. \\ *E-mail: drvsivakumar@yahoo.com
}

(Received August 11, 2013; Accepted September 25, 2013)

\begin{abstract}
Removal of COD and TSS from rice mill wastewater was investigated using continuous electrocoagulation method (CEC). The electrical energy consumption (EEC) of the process was also examined in order to evaluate the economic viability. The Box-Behnken statistical experiment design (BBD) and response surface methodology (RSM) were used to investigate the effects of major operating variables. Initial $\mathrm{pH}$, current density, electrode distance and flow rate were selected as independent variables in BBD while COD removal, TSS removal and EEC were considered as the response functions. The predicted values of responses obtained using the response function was in good agreement with the experimental data. Optimum operating conditions were found to be $\mathrm{pH}$ of 7 , current density of $15 \mathrm{~mA} \mathrm{~cm} \mathrm{c}^{-2}$, electrode distance of $5 \mathrm{~cm}$ and flow rate of $70 \mathrm{ml} / \mathrm{min}$. Under these conditions, greater than $89 \%$ removal of COD and TSS were obtained with EEC value of $7 \mathrm{KWh}$.
\end{abstract}

Key words: Rice mill wastewater, Electrocoagulation, Box-Behnken design, Model development, Validation

\section{INTRODUCTION}

The treatment of wastewater generated by industry remains a significant environmental pollution issue because of its huge quantity and its diversity. Among various kinds of industries, rice industry is considered as one of the most polluting sectors in India in terms of effluent composition as well as volume of discharge. Disposal of this harmful wastewater into receiving water bodies can be toxic to aquatic life. In addition, they pose a problem because they may be mutagenic and carcinogenic and can cause severe damage to human beings. ${ }^{1}$ Numerous research reports were available in literature regarding treatment of rice industry wastewater such as two stage upflow anaerobic sludge blanket, ${ }^{2}$ immobilized packed bed system ${ }^{3}$ and proton exchange membrane. ${ }^{4}$ However, discharge of wastewater, after application of these treatment methods in industrial level is still questionable due to the presence of considerable amount of toxic matters. Therefore, there is a urgent need to identify new technologies that achieve technically and economically efficient to treat rice industry wastewater.

Last few decades, electrocoagulation process is playing a more prominent role in the treatment of various wastewaters, because it provides many advantages namely no chemical additives are added to destabilize the emulsion, simple equipment, easy operation, low capital and operating cost and decreased amount of sludge. ${ }^{5}$ Electrocoagulation is a process consisting of creating a floc of metallic hydroxides within the effluent to be treated by electrodissolution of a soluble anode and the most common used anode materials for electrocoagulation is stainless steel (SS) due to it's characterisitics such as cheap and readily available. Moreover, electrocoagulation technique uses a direct current source between metal electrodes (SS) immersed in polluted water and it causes the dissolution of metal plates. The metal ions, at an appropriate $\mathrm{pH}$, can form wide ranges of coagulated species and metal hydroxides that destabilize and aggregate the suspended particles or precipitate and adsorb dissolved contaminants. ${ }^{6}$ An extensive survey shows that, different industry wastewaters were effectively treated by electrocoagulation technique and it was found that efficiency of treatment process may be enhanced by various operating parameters namely current density, electrode distance and wastewater flow rate. ${ }^{7}$

In conventional multifactor experiments, optimization is usually carried out by varying a single factor while keeping all other factors fixed level. It is not only time-consuming, but also usually incapable of reaching the true optimum due to ignoring the interactions among variables. Thus, it is desirable to develop an acceptable process in shortest possible time using minimum number of runs, men, hours and raw materials. For this purpose, response surface methodology (RSM) was proposed to determine the influences of individual factors and their interactive 
influences. ${ }^{8}$ RSM is a statistical technique for designing experiments, building models, evaluating the effects of several factors, and searching optimum conditions for desirable responses. The main advantage of this method of other statistical experimental design methods is the reduced number of experiments trials needed to evaluate multiple parameters and their interactions. ${ }^{9}$ However, best of our knowledge, it was found that there is no research reports are available for the treatment of rice industry wastewater using continuous electrocoagulation process (CEC) via response surface methodology.

Hence, in this present study an attempt was made to investigate the individual and interactive effect of process variables such as initial $\mathrm{pH}$, current density, electrode distance and wastewater flow rate on chemical oxygen demand (COD) and total suspended solids (TSS) removal and electrical energy consumption (EEC) from rice industry wastewater using continuous electrocoagulation treatment technique. Ressponse surface methodlogy (RSM) coupled with fours factor three level Box-Behnken response surface design (BBD) was used to develop mathematical models in order to predict the response values under the experimental range used in this study.

\section{EXPERIMENTAL}

The chemical composition and some properties of the rice mill wastewater (Collected from Erode, TamilNadu) used in this study are listed in Table 1. Hydrochloric acid $(1 \mathrm{~N}, 0.1 \mathrm{~N})$ and sodium hydroxide $(1 \mathrm{~N}, 0.1 \mathrm{~N})$ solutions were prepared for $\mathrm{pH}$ adjustment. Analytical grade chemicals were used for the preparation of all the solutions.

Picture of continuous electrocoagulation reactor was shown in Fig. 1. An working volume of 3L tank (Acrylic made) was used to conduct the continuous electrocoagulation (CEC) experiments. Stain steel (SS) plates with effective surface area of each electrode having $108 \mathrm{~cm}^{2}$ were used as anode and cathode. The top of electrodes were connected to DC power supply equipment and it was used to adjust the desired current density. In each run, $1.6 \mathrm{~L}$ of wastewater was placed into the reactor and all the runs were performed at constant, stirring speed of $250 \mathrm{rpm}$ and $1 \mathrm{~g} / \mathrm{l}$ of $\mathrm{NaCl}$ as a supporting electrolyte. Peristaltic pump

Table 1. Characteristics of rice industry wastewater

\begin{tabular}{cc}
\hline Characteristics & Values \\
\hline COD $(\mathrm{mg} / \mathrm{l})$ & 2200 \\
Initial pH & 4.98 \\
TSS (mg/l) & 768 \\
\hline
\end{tabular}

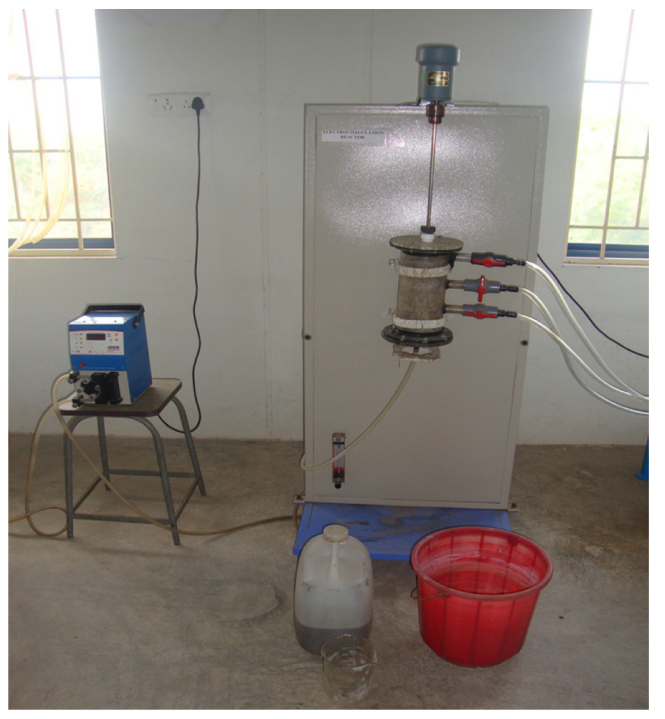

Figure 1. Picture of continuous electrocoagulation reactor.

(Made: miclins) was used to vary the inlet flow rate of the wastewater. After the CEC treatment process (steady state), supernatant wastewater was collected and it was used for determination of and COD and TSS.

The COD and TSS analysis were carried out by methods described by American Public Health Association (APHA). The removal efficiency (RE) of COD and TSS was calculated by using the following equation. ${ }^{10}$

$$
R E=\left(\frac{c_{0}-c_{e}}{c_{0}}\right) \times 100
$$

where, $c_{0}$ and $c_{e}$ is the initial and final concentrations of COD and TSS respectively. Electrical energy consumption (EEC) during continuous electrocoagulation process was calculated as follows,

$$
\begin{aligned}
& \text { Electrical energy consumption }(\mathrm{KWh}) \\
& \quad=\operatorname{volts}(\mathrm{V}) \times \operatorname{amperes}(\mathrm{A}) \times \text { retention time }(\mathrm{h})
\end{aligned}
$$

Hydralic retention time of the CEC was calculated by the following equation,

Retention time $(\mathrm{min})$
$=$ Volume of the reactor $(\mathrm{ml}) /$ Volumetric flow rate $(\mathrm{ml} / \mathrm{min})$

In this present study, RSM was used to investigate the influence of operating variables on continuous electrocoagulation treatment process efficiency and to find the most suitable combination of variables resulting in maximum COD and TSS removal efficiency with minimum electrical energy consumption. The BBD with four factors and three levels (including five replicates at the cen- 
tre point for estimation of errors) was used to evaluate the main and interaction effects of the factors and to fit a second-order model with quadratic terms. In this present study, four important operating parameters such as initial $\mathrm{pH}$, current density, electrode distance and wastewater flow rate were considered as the independent variables, while COD $\left(\mathrm{Y}_{1}\right)$ and TSS $\left(\mathrm{Y}_{2}\right)$ removals and EEC $\left(\mathrm{Y}_{3}\right)$ were the responses. Initial $\mathrm{pH}\left(\mathrm{X}_{1}\right)$ was varied between 6-8, current density $\left(\mathrm{X}_{2}\right)$ varied from $5-25 \mathrm{~mA} \mathrm{~cm}^{-2}$, electrode distance $\left(\mathrm{X}_{3}\right)$ was varied between $4-6 \mathrm{~cm}$ and flow rate $\left(\mathrm{X}_{4}\right)$ was ranged from 50 to $100 \mathrm{ml} / \mathrm{min}$. The low, middle, and high levels of each variable were designated as $-1,0$, and +1 , respectively. For statistical calculations, the process variables were coded at three levels $(-1,0$ and +1$)$ and the coding was done by the following equation: ${ }^{11}$

$$
x_{i}=\frac{X_{i}-X_{z}}{\Delta X_{i}} \quad i=1,2,3 \ldots \ldots k
$$

where $x_{i}$, is the dimensionless value of an independent variable; $X_{i}$, the real value of an independent variable; $X_{z}$, the real value of an independent variable at the centre point; and $X_{i}$, step change of the real value of the variable $i$. Twenty nine experiments were designed with five replications by using the following equation,

$$
N=2 K(K-1)+C_{0}
$$

where, $K$ is number of factors and $C_{0}$ is the number of central point. An empirical second-order polynomial model (Y) (response function) for predicting the optimal point was in the following form:

$$
Y=\beta_{0}+\sum_{j=1}^{k} \beta_{j} X_{j}+\sum_{j=1}^{k} \beta_{j j} X_{j}^{2}+\sum_{i} \sum_{<j=2}^{k} \beta_{i j} X_{i} X_{j}+e_{i}
$$

where, $Y$ is the response; $X_{i}$ and $X_{j}$ are variables ( $i$ and $j$ range from 1 to $k$ ); $\beta_{0}$ is the model intercept coefficient; $\beta_{\mathrm{j}}$, $\beta_{\mathrm{jj}}$ and $\beta_{\mathrm{ij}}$ are interaction coefficients of linear, quadratic and the second-order terms, respectively; $k$ is the number of independent parameters ( $k=4$ in this study); and $e_{i}$ is the error. Moreover, adequcy of developed mathematical models were investigated by the pareto analysis of variance (ANOVA) and developed mathematical models were used to plot the response surface contour graphes in order to study the interactive effect of independent variables on the responses. ${ }^{12}$ Finally, numerical optimization was made on BBD results in order to obtain the best operating conditions for effective treatment process interms of removal efficiency and economic viability.

\section{RESULTS AND DISCUSSION}

In this present study COD removal, TSS removal and electrical energy consumption (EEC) from rice mill wastewater was investigated by continuous electrocoagulation method using stainless steel as an electrode. The effects of process variables such as initial $\mathrm{pH}$, current density, electrode distance and flow rate on the efficiency of treatment process was investigated using RSM according to BoxBehnken experimental design (BBD). Different response functions such as linear, interactive, quadratic and cubic models were used to correlate the BBD experimental data and to obtain the best suitable mathematical model to represent the continuous electrocoagulation process. To decide about the adequacy of the models to represent present treatment process, two different tests namely sequential model sum of squares and model summary statistics ${ }^{13}$ were carried out in the present study. Cubic model was not recommended for this system due to insufficient points to estimate the coefficients for this type of the model. Sequential model sum of squares and model summary statistics indicated that the quadratic model provided the best fit to experimental data with the lowest standard deviation, the highest correlation coefficient $\left(\mathrm{R}^{2}\right)$, adjusted $\mathrm{R}^{2}$, predicted $\mathrm{R}^{2}$ values, and the lowest $\mathrm{p}$ value. ${ }^{14}$ Therefore, the quadratic model was chosen for further analysis. BBD experimental data were used for determining of the response function coefficients for each independent variable and final developed mathematical models obtained in terms of coded factors are given below

$$
\begin{aligned}
\mathrm{Y}_{1}= & 97.42+9.22 \mathrm{~A}+8.95 \mathrm{~B}-8.05 \mathrm{C}-10.57 \mathrm{D}+1.28 \mathrm{AB} \\
& -7.66 \mathrm{AC}+7.82 \mathrm{AD}-11.02 \mathrm{BC}+0.080 \mathrm{BD}+0.70 \mathrm{CD} \\
& -30.03 \mathrm{~A}^{2}-12.37 \mathrm{~B}^{2}-20.44 \mathrm{C}^{2}-12.09 \mathrm{D}^{2}
\end{aligned}
$$

$$
\begin{aligned}
\mathrm{Y}_{2}= & 88.55+9.26 \mathrm{~A}+9.24 \mathrm{~B}-8.55 \mathrm{C}-10.71 \mathrm{D}+0.30 \mathrm{AB} \\
& -7.49 \mathrm{AC} 7+8.24 \mathrm{AD}-10.03 \mathrm{BC}-0.52 \mathrm{BD}+1.76 \mathrm{CD} \\
& -26.41 \mathrm{~A}^{2}-8.98 \mathrm{~B}^{2}-17.53 \mathrm{C}^{2}-9.30 \mathrm{D}^{2} \\
\mathrm{Y}_{3}= & 8.09+0.23 \mathrm{~A}+6.09 \mathrm{~B}+0.13 \mathrm{C}-3.26 \mathrm{D}-0.078 \mathrm{AB} \\
& -0.29 \mathrm{AC}+0.12 \mathrm{AD}-0.67 \mathrm{BC}-2.42 \mathrm{BD}-0.11 \mathrm{CD} \\
& +0.84 \mathrm{~A}^{2}+6.001 \mathrm{E}-003 \mathrm{~B}^{2}-0.39 \mathrm{C}^{2}+1.18 \mathrm{D}^{2}
\end{aligned}
$$

Where $Y_{1}, Y_{2}$ and $Y_{3}$ are COD removal, TSS removal and electrical energy consumption respectively. The statistical significance of the response functions $\left(\mathrm{Y}_{1}-\mathrm{Y}_{3}\right)$ was checked by F-test, and the ANOVA results for response surface quadratic model and model terms are summarized in Table 2. The model $\mathrm{F}$ values and very low probability 
Table 2. ANOVA table for responses

\begin{tabular}{|c|c|c|c|c|c|c|}
\hline \multirow{2}{*}{ Source } & \multicolumn{2}{|c|}{ COD removal $(\%)$} & \multicolumn{2}{|c|}{ TSS removal (\%) } & \multicolumn{2}{|c|}{ EEC (\%) } \\
\hline & F value & $P$ value & F value & $P$ value & F value & $P$ value \\
\hline Model & 93.92 & $<0.0001$ & 91.87 & $<0.0001$ & 69.16 & $<0.0001$ \\
\hline A & 106.48 & $<0.0001$ & 121.81 & $<0.0001$ & 1.02 & 0.3293 \\
\hline B & 100.32 & $<0.0001$ & 121.51 & $<0.0001$ & 701.42 & $<0.0001$ \\
\hline $\mathrm{C}$ & 81.20 & $<0.0001$ & 103.84 & $<0.0001$ & 0.34 & 0.5714 \\
\hline $\mathrm{D}$ & 139.90 & $<0.0001$ & 162.91 & $<0.0001$ & 200.62 & $<0.0001$ \\
\hline $\mathrm{AB}$ & 0.69 & 0.4204 & 0.04 & 0.8367 & 0.04 & 0.8486 \\
\hline $\mathrm{AC}$ & 24.49 & 0.0002 & 26.62 & 0.0001 & 0.52 & 0.4824 \\
\hline $\mathrm{AD}$ & 25.54 & 0.0002 & 32.17 & $<0.0001$ & 0.09 & 0.7724 \\
\hline $\mathrm{BC}$ & 50.68 & $<0.0001$ & 47.67 & $<0.0001$ & 2.85 & 0.1136 \\
\hline $\mathrm{BD}$ & 0.00 & 0.9595 & 0.13 & 0.7257 & 36.81 & $<0.0001$ \\
\hline $\mathrm{CD}$ & 0.20 & 0.6581 & 1.46 & 0.2470 & 0.08 & 0.7865 \\
\hline $\mathrm{A}^{2}$ & 610.11 & $<0.0001$ & 536.15 & $<0.0001$ & 7.22 & 0.0177 \\
\hline $\mathrm{B}^{2}$ & 103.54 & $<0.0001$ & 61.92 & $<0.0001$ & 0.00 & 0.9850 \\
\hline $\mathrm{C}^{2}$ & 282.79 & $<0.0001$ & 236.12 & $<0.0001$ & 1.58 & 0.2299 \\
\hline $\mathrm{D}^{2}$ & 98.89 & $<0.0001$ & 66.49 & $<0.0001$ & 14.28 & 0.0020 \\
\hline C.V. $\%$ & \multicolumn{2}{|c|}{4.66} & \multicolumn{2}{|c|}{4.63} & \multicolumn{2}{|c|}{9.09} \\
\hline PRESS & \multicolumn{2}{|c|}{772.93} & \multicolumn{2}{|c|}{680.69} & \multicolumn{2}{|c|}{49.62} \\
\hline AP & \multicolumn{2}{|c|}{31.31} & \multicolumn{2}{|c|}{31.63} & \multicolumn{2}{|c|}{35.31} \\
\hline
\end{tabular}

value (0.0001) indicated that the developed mathematical model was statistically significant and model equation can adequately used to describe the continuous electrocoagulation treatment method under a wide range of operating conditions. The $p$ values are used to estimate whether $\mathrm{F}$ value is large enough to indicate statistical significance and used to check the significance of each coefficient. $p$ values lower than 0.05 indicate that the model and model terms are statistically significant.

Furthermore the study of contour plots and the regression equation highlight certain interactions between the selected parameters as well as their individual effects. ${ }^{15}$ The analysis showed that the form of the model chosen to explain the relationship between the factors and the response is correct and can be used to navigate the design space. The value of the adequate precision is a measure of the signal (response) to noise (deviation) ratio. In this present study, the ratio was found to be greater than 31 for the responses, which indicates the adequate signal. ${ }^{16}$ Moreover, the adequacy of developed mathematical models to represent the CEC process was done by constructing diagnostic plots such as predicted versus actual plot (Fig. 2) and Normal \% probability graphs (Fig. 3). The data points lies very close to the diagonal line for both the graphs and it depicts a good relationship between experimental and predicted data. Therefore the quadratic model can be used to represent the continuous electrocoagulation process to treat rice mill industry wastewater.

\section{Effect of Process Variables on Responses}

Factors giving significant interaction effects in the new simplified fitted models were chosen for the axes of the response surface plots to account for curvature of the surfaces. So that, from the developed regression models, response surface contour plots were plotted to assess ${ }^{17}$ the effects of the independent variables on the responses and it was given in Fig. 4-5.

\section{Effect of Initial pH}

In electrocoagulation process, $\mathrm{pH}$ is a crucial parameter which affects the performance of the treatment efficiency. In order to investigate the effect of $\mathrm{pH}$ on responses, electrocoagulation treatment was performed at various $\mathrm{pH}$ ranges (6-8). Fig. 4 illustrates the response surface assuming the initial $\mathrm{pH}$ and the current density as independent factors. From the results, it was found that COD and TSS removals were increased with the increase in initial $\mathrm{pH}$ from 6 to $7 .{ }^{18}$ Thereafter, there is a negative effect on removal efficiency of COD and TSS. It is evident that there is an obvious interaction between the initial $\mathrm{pH}$ and the current density on COD and TSS removal. Whereas, $\mathrm{pH}$ shows negligible effect on electrical energy consumption in continuous electrocoagulation process. 

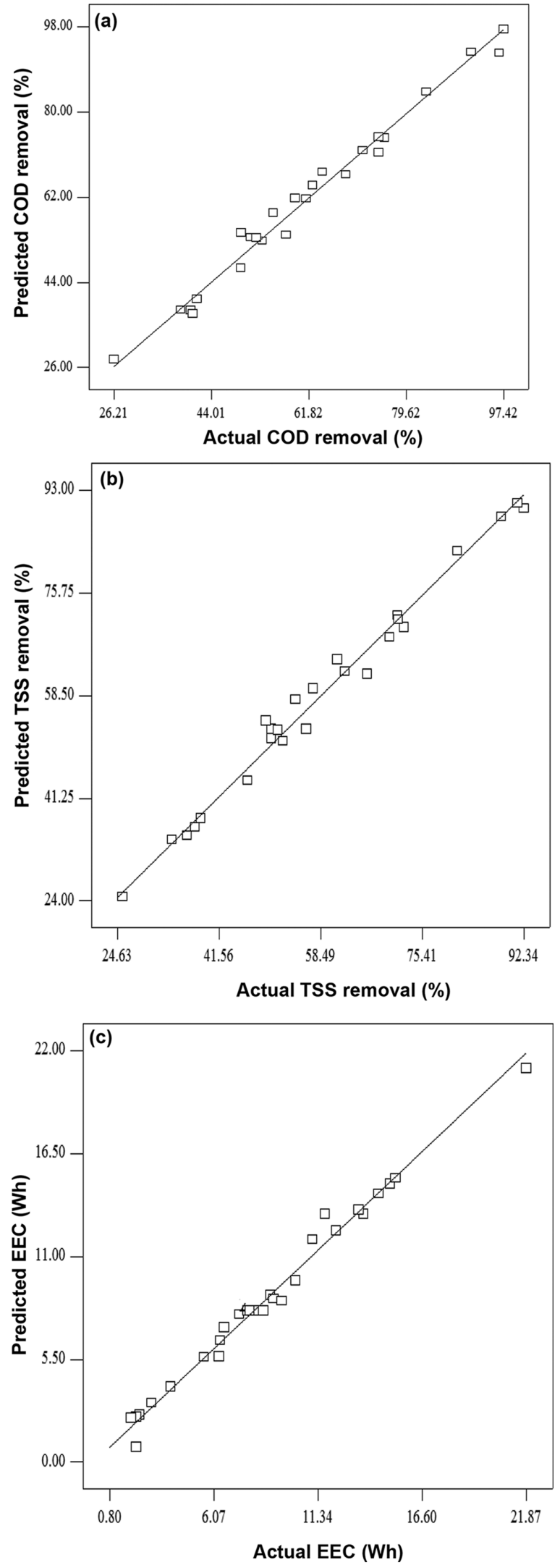

Figure 2. Predicted versus actual plot for responses.
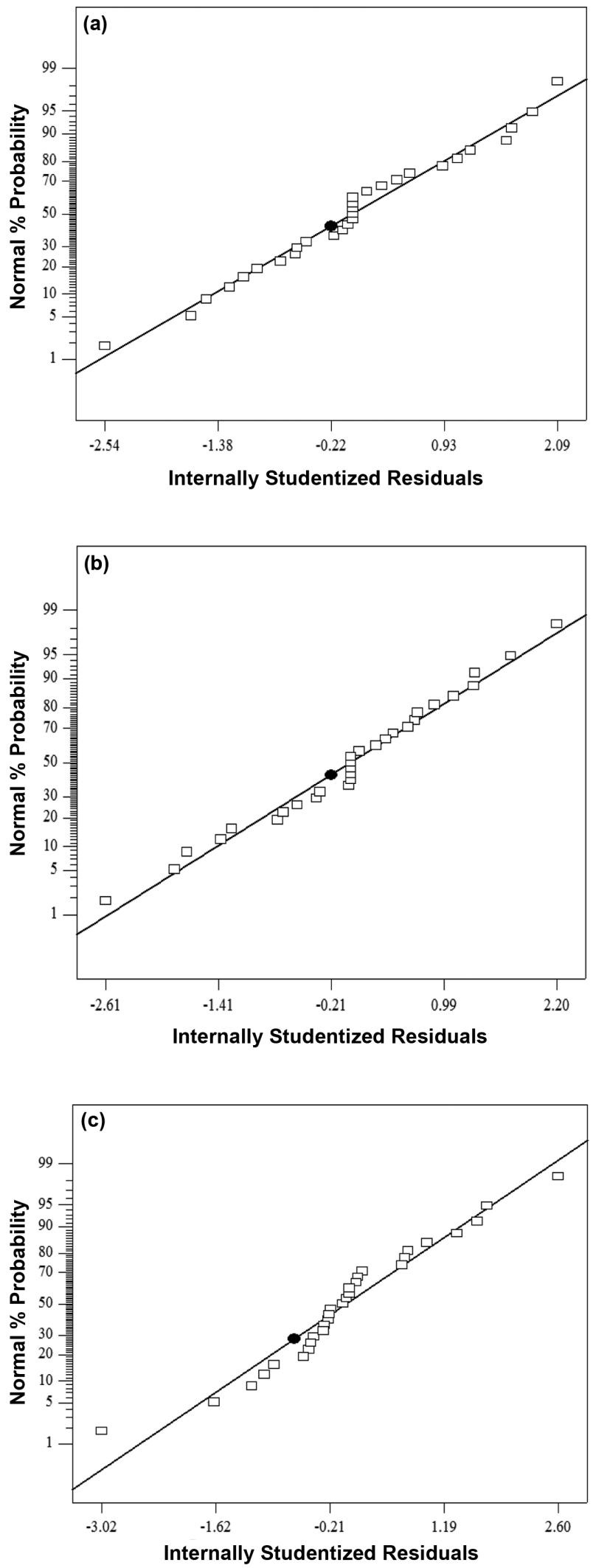

Figure 3. Normal \% probability plots for responses: (a) COD removal; (b) Turbidity removal; (c) EEC. 

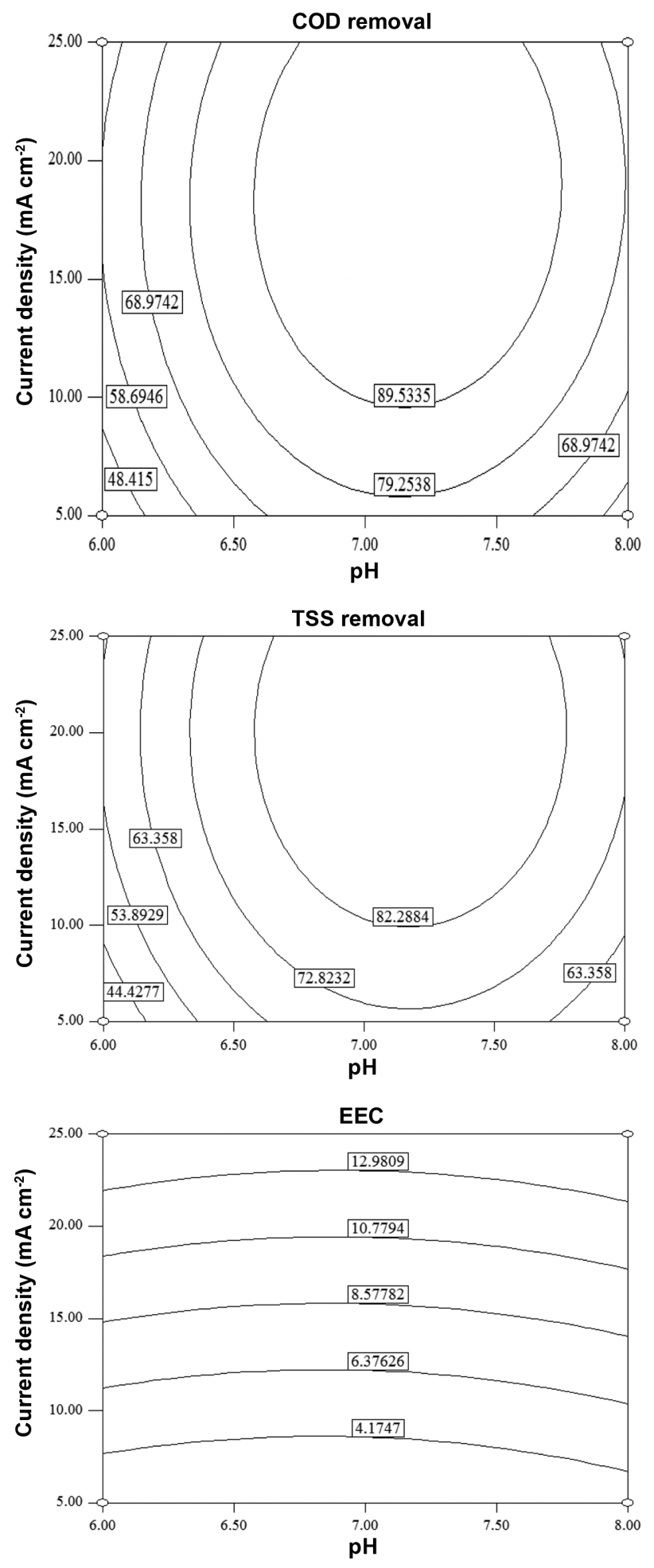

Figure 4. Effect of initial $\mathrm{pH}$ and current density on responses.

\section{Effect of Current Density}

Current density is an important operatring parameter in electrocoagulation treatment process, which is greatly affect

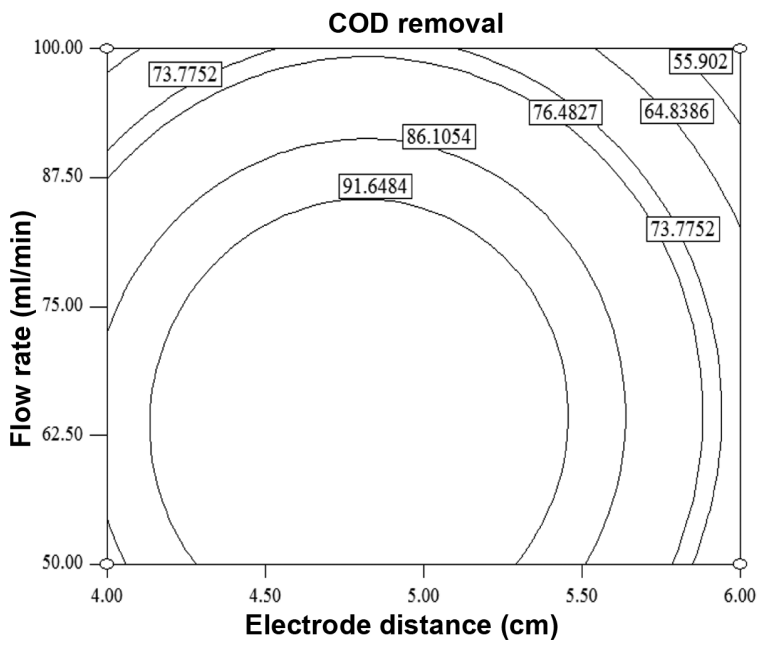

TSS removal

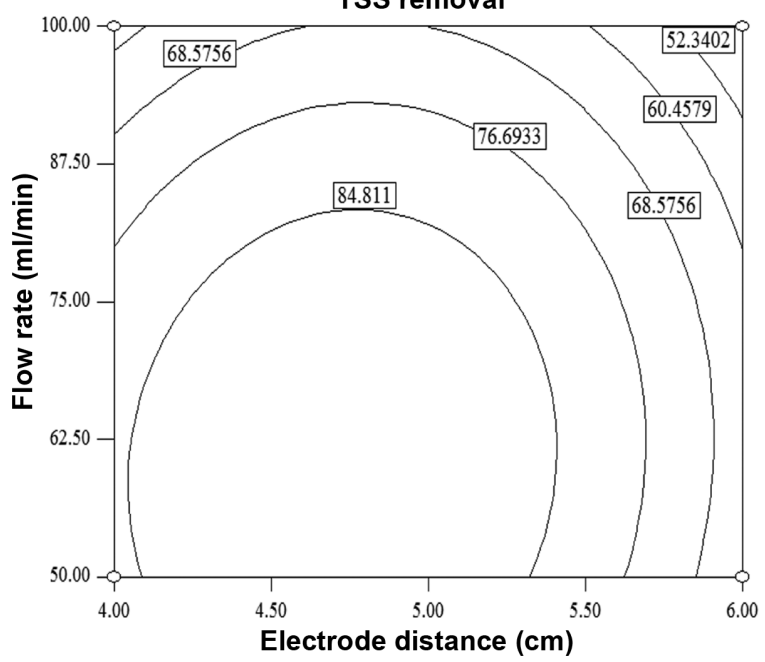

EEC

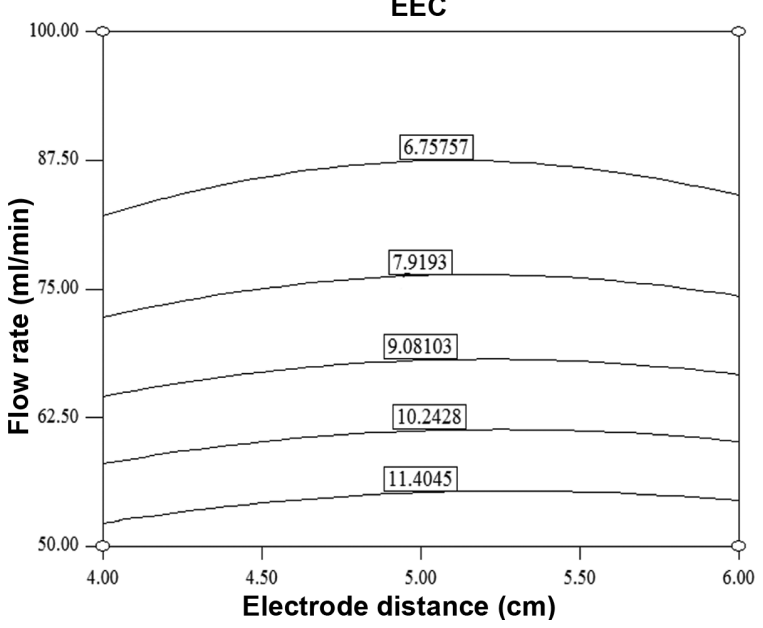

Figure 5. Effect of electrode distance and flow rate on responses.

the efficiency of treatment process and economy of the process. To investigate the effect of current density on electrocoagulation process, experiments were carried out 
at different current densities $\left(5-25 \mathrm{mAcm}^{-2}\right)$ and the observation is depicted in Fig. 4. As shown in Fig. 4, it was observed that the COD and TSS removal increased with increasing current density upto $15 \mathrm{~mA} \mathrm{~cm}{ }^{-2}$. This is mainly due to, increase in current density produces metal hydroxides, which contains strong affinity towards dispersed and colloidal particles in the wastewater and results in coagulation, which effectively removes the COD and TSS. ${ }^{19}$ Thereafter, there is almost constant removal efficiencies beyond current density of $15 \mathrm{~mA} \mathrm{~cm}{ }^{-2}$. Meanwhile, current density shows strong effect on electrical energy consumption that is to say EEC linearly increases with increasing current density throughout the experiment.

\section{Effect of Electrode Distance}

Electrode distance is a vital factor to determine the treatment efficiency of electrocoagulation process. In order to evaluate its effect, experiments were performed at a range of electrode distance $(4-6 \mathrm{~cm})$ and the results are graphically shown in Fig. 5. From the results it was found that, the removal efficiencies of COD and TSS were increases with increasing electrode distance upto $5 \mathrm{~cm}$. This can explained the fact that, small electrode spacing minimizes ohmic losses permitting relatively high current densities, in return high reaction rate and enhance the removal efficiency. Thereafter, beyond electrode distance of $5 \mathrm{~cm}$, there is a drastic decrease in removal efficiencies. ${ }^{20}$ While, electrode distance shows significant effect on electrical enrgy consumption.

\section{Effect of Wastewater Flow Rate}

In the electrocoagulation process, the inlet flow rate is an essential factor which can influences the overall performance of the electrocoagulation process. To evaluate it's effect on treatment efficiency, experiments were done at different flow rates $(50-100 \mathrm{ml} / \mathrm{min})$ and results are shown in graphically Fig. 5. The obtained results indicates that, the removal of COD and TSS were constant up to flow rate range $85 \mathrm{ml} / \mathrm{min}$. Thereafter, there is a decrease in removal efficiencies due to the ineffective contact between metal hydroxides and counter ions presence in the wastewater. ${ }^{21}$ Meanwhile, electrical energy consumption is decreased with increasing flow rate.

\section{Optimization}

According to the BBD results, the optimal operating conditions to obtain maximum COD and TSS removal effciciencies with minimum electrical consumption from rice industry wastewater using continuous electrocoagu- lation treatment process were determined by Derringer's desired function methodology as follows: initial $\mathrm{pH}$ of 7 , current density of $15 \mathrm{~mA} \mathrm{~cm}^{-2}$, electrode distance of $5 \mathrm{~cm}$ and flow rate of $70 \mathrm{ml} / \mathrm{min}$. Under these conditions, the predicted responses were $97.41 \%, 89.09 \%$ and $7.24 \mathrm{KWh}$ for COD removal, TSS removal and EEC respectively with a desirability value of 0.886 . Additional experiments (using the predicted optimum conditions) were carried out in order to validate the optimum conditions which shows the experimental responses values $(97 \%, 89 \%$ and $7 \mathrm{KWh}$ for $\mathrm{COD}$ removal, TSS removal and EEC respectively). The good correlation between these observed results and predicted values indicate the reliability of BBD incorporate with desirability function method ${ }^{22}$ and it could be effectively used to optimize the parameters in continuous electrocoagulation process.

\section{CONCLUSION}

The application of a four factor, three-level Box-Behnken experimental design combining with RSM helped in reaching the global optimal solution for maximizing COD and TSS removal with minimum electrical energy consumption from rice industry wastewater using continuous electrocoagulation treatment technique. The proposed mathematical methodology also provided a critical analysis of the simultaneous interactive effects of independent variables, such as initial $\mathrm{pH}$, current density, electrode distance and flow rate for better understanding of the treatment process using SS electrodes. The optimum variables were found to be initial $\mathrm{pH}$ of 7, current density of $15 \mathrm{~mA} \mathrm{~cm}{ }^{-2}$, electrode distance of $5 \mathrm{~cm}$ and flow rate of $70 \mathrm{ml} / \mathrm{min}$. Under these conditions, the predicted responses were $97 \%$, $89 \%$ and $7 \mathrm{KWh}$ for COD removal, TSS removal and EEC respectively. The adequacy of the developed mathematical model was checked with the various descriptive statistics. Predicted values obtained using the quadratic model equations were in very good agreement with the observed values. These results indicates that continuous electrocoagulation process could be effective pre-treatment method to treat rice industry wastewater in terms of high removal efficiency of COD and TSS as well as economic viabily.

Acknowledgments. The authors are thankful to University Grant Commission, Government of India, for financial support (F.No:39-853/2010) to fabricate and use the experimental setup. And the publication cost of this paper was supported by the Korean Chemical Society. 


\section{REFERENCES}

1. Thirugnanasambandham, K.; Sivakumar, V.; Prakash Maran, J. J. Serb. Chem. Soc. 2013, DOI: 10.2298/JSC130201053T.

2. Rajesh, G.; Bandyopadhyay, M.; Das, D. Biopro. Eng. 1999, 21, 113.

3. Manogari, R.; Daniel, D.; Krastanov, A. Ecol. Eng. Environ. Protect. 2008, 1, 30.

4. Manaswini, B.; Partha S. J.; Tanaji T. M.; Ghangrekar, M. M. Bioelectrochemistry 2010, 79, 228.

5. Sridhar, R.; Sivakumar, V.; Prince Immanuel, V.; Prakash Maran, J. J. Hazard. Mater. 2011, 186, 1495.

6. Merzouk, B.; Gourich, B.; Sekki, A.; Madani, K.; Chibane, M. J. Hazard. Mater. 2009, 164, 215.

7. Bayramoglu, M.; Kobya, M.; Can, O. T.; Sozbir, M. Sep. Purif. Technol. 2004, 37, 117.

8. Thirugnanasambandham, K.; Sivakumar, V.; Prakash Maran, J. J. Serb. Chem. Soc. 2013, DOI: 10.2298/JSC130408074T.

9. Bhatti, M. S.; Kapoor, D.; Kalia, R. K.; Reddy, A. S.; Thukral, A. K. Desalination 2011, 274, 74.

10. Muftah, H. E. N.; Sulaiman, A.; Amal, A.; Souzan, M. $J$ Environ. manage. 2009, 91, 180.

11. Prakash Maran, J.; Sivakumar, V.; Sridhar, R.; Prince Imman- uel, V. Ind. Crop. Prod. 2013, 42, 159.

12. Zodi, S.; Potier, O.; Lapicque, F.; Leclerc, J. Desalination 2010, 261, 186.

13. Prakash Maran, J.; Manikandan, S.; Thirugnanasambandham, K.; Vigna Nivetha, C.; Dinesh, R. Carbohyd Polym. 2013, 92, 604 .

14. Olmez, T. J. Hazard. Mater. 2009, 162, 1371.

15. Korbahti, B. K.; Aktas, N.; Tanyolac, A. J. Hazard. Mater. 2007, 148, 83.

16. Jianfeng, F.; Yaqian, Z.; Qiuli, W. J. Hazard. Mater. 2007, 144, 499.

17. Prakash Maran, J.; Sivakumar, V.; Thirugnanasambandham, K.; Sridhar, R. Prep Biochem Biotech. 2013 DOI: 10.1080/ 10826068.2013.791629.

18. Gao, P.; Chen, X.; Shen, F.; Chen, G. Sep. Purif. Technol. 2005, 43, 117.

19. Khalid, B.; Melhem, E. S. J. Chem. Eng. 2012, 198, 201.

20. Ravikumar, K.; Pakshirajan, K.; Swaminathan, T.; Balu, K. Chem. Eng. J. 2005, 105, 131.

21. Tak Hyun, K.; Chulhwan, P.; Eung Bai, Shin.; Sangyong, K. Desalination 2002, 150, 165.

22. Thirugnanasambandham, K.; Sivakumar, V.; Prakash Maran, J. Carbohyd. Polym. 2013, 97, 451. 